Scientiæ studia, São Paulo, v. 11, n. 3, p. 677-85, 2013

\title{
Os embates do encontro
}

\author{
Stelio MARRAS
}

\section{Luso-brazilian encounters of the sixteenth century: a styles of thinking approach}

Alessandro Zir

Fairleigh Dickinson University Press

Madison-Teaneck, 2011, 121 págs.

O tema é o encontro. O Velho Mundo ibérico seiscentista encontra o Novo Mundo e aí mesmo reencontra a si próprio, suas utopias e distopias, seus monstros e seus motivos edênicos, suas escatologias e seus fados - como se o imaginado adiantasse o real com que os conquistadores vieram a topar na América portuguesa. Alessandro Zir, pesquisador ligado à Universidade Federal do Rio Grande do Sul, serve-se da abordagem dos estilos de pensamento (styles of thinking) - nessa expressão de Ian Hacking (2002), autor que Zir elege como espécie de mentor -, criada para melhor captar o curso histórico e suas mudanças e como uma estratégia teórica a um só tempo pertinente à filosofia e à história da ciência. Essa estratégia é ela mesma um encontro, incluindo-se aí o sentido de embate, disputa e experiência, tal como prevê a semântica do termo inglês "encounter", constante no título do livro e muito bem escolhido. É que para além dos embates com os monstros revividos no outro lado do Atlântico, logo se destaca o embate, visando melhor conhecer o assunto em pauta, entre essa abordagem dos estilos de pensamento e aqueles antigos (ou nem tanto) modos mentais que recolhemos nas narrativas de viajantes, colonizadores e missionários do século xvi. Com efeito, o embate é, de saída, metodológico e epistemológico, podendo ser resumido na seguinte pergunta: como encarar hoje aquelas narrativas de seres e feitos fantásticos sem as reduzirmos à compreensão anacrônica naturalista ou da ciência moderna oficial - isto é, purificada de incertezas e mediações, para aqui já me valer da concepção de ciência moderna oficial de Bruno Latour (1994) - que faz do passado a imagem do bizarro e da confusão indistinta de agentes e suas relações causais? Desafio este que também pode ser traduzido pelo "princípio de irredução", tal como proposto tanto por Latour quanto pela filósofa belga Isabelle Stengers (2002), autora íntima e cada vez mais central dos science studies, embora não considerada por Zir. Em todo caso, Zir prepara-se mui- 
to bem para a tarefa, cujo êxito, compartilhado com o leitor, culminará em um entendimento, por assim dizer, mais realista (senão neorealista) do fantástico.

Para tal, o livro pretende inscrever-se na área dos science studies, isto é, dos novos estudos de ciência ou, sobretudo, daqueles capitaneados por Hacking. Creio que essa pretensão se justifica especialmente porque o autor visa retirar do exotismo pueril aquelas narrativas seiscentistas permeadas de monstros, milagres e relatos prodigiosos de signo sobrenatural. Trata-se então de uma empresa intelectual que recusa o relativismo incomensurável ou incomunicável entre realidades - aquelas do passado e as nossas contemporâneas - que se tornaram historicamente díspares. Entendo que essa recusa, cujo desafio é conectar, mas sem reduzir (seja a redução a termos transcendentais, seja a redução a uma das tradições sob embate), cumpre um dos pontos centrais das promessas dos science studies. Trilhar esse caminho implica reabrir, como de fato faz o autor, questões ou controvérsias que a modernidade julgava ter superado em nome de verdades que se estabeleceriam de modo definitivo em caixaspretas. No mesmo sentido, implica evitar o famigerado anacronismo histórico, mas sem com isso obnubilar a assunção de um ponto de vista situado; no caso, a inevitável perspectiva de quem, na modernidade atual, aventura-se a abordar aquele passado. Pode-se bem imaginar que essa trilha é delicada e sinuosa, penosa e difícil de percorrer, potencialmente abundante de desvios fáceis, riscos de toda sorte e enganos ingênuos. O que é dizer que é ingênua a análise que pretende descrever como ingênuas aquelas experiências que se tornaram estranhas a nós.

É verdade que muitos historiadores, filósofos e antropólogos, já ao longo do século xx, vieram chamando a atenção para esses riscos. E se o relativismo (em suas diversas facetas e transformações) voltava a insinuar-se como solução, ele cada vez mais vai naufragando na paralisia do conhecimento, já que a caracterização dura, fechada e incontroversa das realidades não permite conexões entre elas, senão grosseiramente redutoras, tornando assim impossível ou pobre demais a empresa comparativa, e, por extensão, o próprio desdobramento do real por meio da atividade de conhecer. Muitos dos chamados autores pós-modernos herdaram e tentaram consolidar essa solução relativista, inclusive estendendo-a para o problema da legitimidade da representação de outras realidades por meio da ficção autoral, aí mesmo denunciada. E o fizeram abandonando a razão, ao invés de alargá-la, face à riquíssima diversidade dos povos, como queria Marcel Mauss, quando da inauguração francesa da antropologia em fins do século xıx. Mas, em fins do século xx, tornou-se vigente a falação pós-moderna fastidiosa que pretendeu reduzir todo e qualquer conhecimento sobre o real a construções ficcionais. Seria o fim do realismo, da objetividade, senão mesmo da história. Ocorre, contudo, que em pouco tempo a história não se mostrou finita, e o realismo e a objetividade já indicavam claramente que suas bases podiam sim ser reformadas, de modo a 
logo pôr-nos a salvo daquela atmosfera cética e irônica dos pós-modernos. Aliás, considerando a relativa pertinência da crise do conhecimento apontada pelos pós-modernos, mas indicando soluções muito diferentes para as diferenças, lembremos, junto com Latour e Stengers, as obras dos antropólogos contemporâneos Marilyn Strathern (a partir dos povos da melanésia) e Eduardo Viveiros de Castro (a partir dos ameríndios amazônicos). Mas se os pós-modernos não conseguiram fundar e fundamentar soluções vigorosas e promissoras, puderam, entretanto, ao menos (e isso já não é pouco) bem escancarar os impasses a que chegaram as noções, por exemplo, de real e objetivo. Os science studies avançaram por essa senda, mas sistematicamente recusando produzir conhecimento pelo reforço de dualismos estanques a partir de termos supostamente irreconciliáveis, tais como entre o real e o ficcional, o dado e o construído, o objetivo e o subjetivo, o cosmos e a política, a natureza e a sociedade, não humanos e humanos, nós e os outros (incluindo os outros que nossa própria tradição histórica de sentido unilinear cuidou distanciar, precisamente esses nós outros que fazem o objeto do trabalho de Zir).

Com efeito, não parece outro o caminho tomado por Zir para reabrir as controvérsias de ontologia e epistemologia em estudos coloniais, como em torno da noção de natureza. Pois o que seria a natureza para aqueles portugueses seiscentistas, cujo material integra o corpus recortado pelo autor? Como abordar essa noção sem recorrer à "purificação oficial moderna" - conforme expressão de Latour (1994), autor central dos science studies, embora não assuma centralidade, nem dele sejam extraídas consequências, neste trabalho de Alessandro Zir -, purificação que distingue a existência desde sempre (mas só percebida e devidamente manejada pelos modernos) de dois domínios prematuramente purificados e autorreferentes, a saber, o da natureza não humana em contraste ao da sociedade humana? Como ler aqueles autores do século XVI sem simplesmente situá-los como pré-modernos, ainda anteriores à separação oficial entre sujeito e objeto, ainda à espera de um mundo que se desencantaria para que enfim fosse inaugurada a era da ciência e do progresso purificada de toda injunção sobrenatural e subjetivista? Como abordar o fantástico sem reduzi-lo ao delírio de índios ou de desterrados e aventureiros europeus? Na trilha de Ian Hacking, Zir adota a mediação metodológica dos estilos ou modos de pensamento para falar do real que hoje tanto nos aparece como fantasioso, exótico ou ingênuo. Interpreta assim os textos a partir de figuras de retórica (analogias, metáforas, oximoros) que serviram de recursos para que o estilo de pensamento da época expressasse a realidade desse e outros mundos, incluindo, evidentemente, a realidade dos encontros. Creio tratar-se da estratégia de submeter o entendimento dos conteúdos (as ontologias de monstros e de todo um mundo animado de seres sobrenaturais) à compreensão das formas e condições epistêmicas (ou mentalidades, dirão talvez os historiadores herdeiros da Nova His- 
tória) que permitiam a eficácia da veiculação e do agenciamento daquelas ontologias. Tão a propósito, entendo que essa acertada estratégia muito se aproxima da adotada por Alcir Pécora (1999) na leitura da epistolografia jesuítica produzida já desde o início da colonização ibérica no Brasil. Ou seja, para hoje bem compreendermos aquela produção epistolar seiscentista, sem expedi-la para o museu do exotismo, é preciso antes que nos apercebamos das formas e condições dos modos de enunciação então vigentes. Impossível acessar corretamente os conteúdos, se não se considerar as formas. É como de fato faz Pécora em seu "Cartas à segunda escolástica", onde considera então a "estrutura formal" retórica do "viés renascentista e jesuítico" (1999, p. 373) como em relação às ars dictaminis, que informavam a retórica das cartas jesuíticas, havendo na eleição do gênero uma "implicação epistemológica" (p. 373). São regras retóricas ou protocolos do que escrever, para qual finalidade e como fazê-lo. Sem esse cuidado do pesquisador que se aventura a decifrar o passado, o risco, nada desprezível, é o do anacronismo, como, por exemplo, operar a decodificação em termos realistas ou fantásticos, laicos ou místicos, objetivistas ou subjetivistas, tal como hoje entendemos em relação a esses gêneros. Em uma palavra, a estrutura formal modula o conteúdo veiculado, não sendo possível, se não quisermos incorrer em erros de interpretação, considerar uma dimensão sem a outra. Impossível, portanto, avaliar a elocução narrativa sem considerar nela a sua metanarrativa, por assim dizer. Ou, como conclui Pécora em relação à epistolografia jesuítica, "supõe-se aqui que a construção da forma já faz parte da narrativa da história” (1999, p. 410). Neste sentido, Zir faz como Pécora em relação aos jesuítas, destacando, em seu caso, as formas neoplatônicas do renascimento italiano, que se estende à Europa (incluindo Portugal).

O trabalho de Zir desafia o monstro malfazejo do anacronismo, tão conhecido quanto evitado por historiadores, mas o faz (e já no terreno da antropologia e da filosofia agora inspiradas pelos science studies) de modo a também evitar o pressuposto modernista da separação do real entre o corolário de dualismos que derivam do par natureza/sociedade, par que se pretende universal e explicativo de toda e qualquer realidade. ${ }^{\mathbf{1}}$ Desse modo, suspendendo os dispositivos cognitivos modernos em sua face oficial (mas não oficiosa, como mostra Latour, que é a face do real que mistura elementos heterogêneos ainda antes de sua purificação oficial, e assim permite conexões simétricas com outras realidades), o autor abre passagem para o entendimento do mundo sobrenatural, como as relações entre o visível e o invisível no pensamento cristão neoplatônico, reveladas pelo recurso da analogia, sem, portanto, reduzir aquilo que hoje parece tão estranho aos modernos a epítetos cada vez mais insuficientes à com-

1 Separação que se afirmou, contudo, como garantia para a mistura experimental e proliferante das ciências, conforme o argumento de Latour (1994), inspirado, por sua vez, no trabalho de Shapin e Schaffer (1985). 
preensão, tais como o da fantasia, o do engano e o da crença, que não passam de categorias de acusação dos modernos na qualificação dos outros - relação assimétrica entre "o Ocidente e o resto" (the West and the Rest), na feliz caracterização do antropólogo Marshall Sahlins (1988).

Mas penso que há aqui dois importantes riscos que não podem ser desconsiderados. Um é o de tomar essa mediação dos estilos de pensamento como autorreferente ou fechada sobre si mesma, com o correspondente risco de resvalar para o fosso do relativismo. Para evitá-lo, cabe compreender essa mediação antes como modos de composição do mundo, isto é, como modos (virtualmente infinitos e permeáveis ao novo) de amarrar ou associar elementos (não importa se visíveis ou invisíveis, humanos ou não humanos, naturais ou sobrenaturais, desta ou daquela tradição) que, uma vez bem entretecidos, irão mobilizar causas e efeitos de agentes num cosmos que a um só tempo afeta o devir humano e é por este afetado. Melhor tomá-la, portanto, como modos cosmopolitas (cf. Stengers, 1997). Se essa não parece ser a questão de Zir - ainda que questão cara aos science studies aos quais o mesmo autor declara filiação -, contudo podemos hoje bem compreender (e nesse caso Bruno Latour é decisivo) que a realidade da mistura de ontologias legada pela modernidade ao plano do oficioso, essa realidade não apenas nunca nos foi estranha, mas se torna cada vez mais presente, como espécie de retorno social do recalcado. Ou seja, o real sempre se moveu por composição de agentes (naturais, humanos, sobrenaturais) e não pela oposição ou irredutibilidade dada entre eles. A comparação entre nós contemporâneos e eles antigos se renova precisamente neste plano oficioso dos agenciamentos pragmáticos. Subitamente, então, encontramo-nos todos agora desdobrando - ou temos essa auspiciosa chance, e sob as formas mais diversas, aquilo que Latour (1994) denominou de "a velha matriz antropológica". Essa matriz pode ser definida como a experiência intermitente de deslocamento da ação, o que implica a dificuldade de determinação da fonte ou origem (se humana ou não humana) da ação. Essa dificuldade é que torna simétrica a comparação entre os modernos (the West) e os não modernos (the Rest). Creio que o trabalho de Zir possa ser lido dessa maneira. Ou seja, o que ali flagramos é uma indeterminação (que é necessária, segundo Latour, para que haja troca de propriedades entre agentes de modo a que a ação possa então emergir) sobre quem faz e quem é feito. Onde a ação puramente natural? Onde a puramente sobrenatural? Onde a puramente humana? Iremos ler e reler as narrativas seiscentistas o quanto quisermos, mas irá falhar a interpretação (se moderna apenas em sua face oficial) que assevere residir ali ou aqui a origem da ação, a fonte monocausal da realidade. Ora, o ponto é que, a crer em Latour, também entre nós modernos essa confusão (no sentido etimológico, informado pelo dicionário, de "ação de juntar, reunir, misturar"), ela nos é, sempre foi (porque jamais fomos modernos) muito íntima. É como, por exemplo, tentar determinar se o aquecimento 
global (uma vez plenamente aceito pela comunidade científica, mas há controvérsias) deve-se à ação humana ou à ação não humana. Ou ainda tentar determinar se havia ou não micróbios antes de Pasteur, senão também o falso impasse entre fabricação e realidade, fato e fetiche. ${ }^{2}$ De modo sumário, nosso desafio hoje bem poderia se resumir a desconfiar das filosofias do ser em favor das do devir. ${ }^{3}$ Desconfiar dos contornos (como os que definem esta ou aquela ontologia) em favor das passagens entre elas.

O outro risco (senão o risco posto pelo outro) aparece como talvez mais grave, mas de todo modo ligado ao primeiro. Ele diz respeito àquela submissão das ontologias às epistemologias; no caso, submissão dos modos de existência aos modos de pensar. O problema aí é não conseguir reconhecer impactos das ontologias sobre os modos epistêmicos. Seria perguntar: mas o que acontece com aquele pensamento cristão neoplatônico do Velho Mundo, tal como Zir nos apresenta, quando se encontra (no sentido do embate e da experiência) com os modos indígenas do Novo Mundo? Ora, se o corpus historiográfico a que temos acesso direto, tal o escolhido por Zir, inevitavelmente privilegia a perspectiva de colonizadores e missionários, resta-nos ler esse corpus nas entrelinhas se quisermos tomar um pouco de ciência a respeito do outro lado dos encontros. Ainda que o autor se mostre alerta a não tomar "contextos cognitivos", tais como os dos portugueses no Novo Mundo do século xvi, como "blocos fechados", suas transformações sofridas pelo contato com o pensamento indígena não assumem o foco ou a centralidade do trabalho de Zir, tanto menos de forma sistemática.

Esta ressalva que vou aqui indicando pode simplesmente se resumir à pergunta: mas e os índios? Ou talvez colocar o problema da seguinte maneira: se Colombo descobriu a América (ou Pedro Álvares Cabral o Brasil), igualmente a América descobriu Colombo (como o Brasil para Cabral). O Novo Mundo fez daquele outro um Velho Mundo - ambos se descobrindo, se afetando e reinventando no contato continuado. Não parece verossímil supor que os colonizadores apenas aplicavam - ao invés de experimentarem - as antigas imagens, antigos dispositivos retóricos do Velho Mundo no Novo. E as novidades que advieram do impacto junto a uma nova paisagem, novos seres, incluindo a alteridade com uns índios que tanto se pareciam com humanos? ${ }^{4}$ Quais as ressonâncias e os equívocos entre o cosmos animado dos jesuítas e o cosmos animado dos índios no continente americano? É verdade que em alguns momentos do livro Zir

2 Sobre esses exemplos, ver do próprio Latour, além do citado Jamais fomos modernos (1994), também os artigos: "Por onde andavam os micróbios antes de Pasteur?" e "Da fabricação à realidade: Pasteur e seu fermento de ácido láctico" (2001). Sobre fato e fetiche, ver Latour (2002).

3 Nesse sentido, a obra de Deleuze e Guattari inspira um caminho tão seguro quanto promissor.

4. Questão esta centralmente presente na famosa Controvérsia de Valladolid, em meados do século xvi, que opôs o dominicano Bartolomé de las Casas ao defensor do domínio espanhol sobre os índios Juan Ginés de Sepúlveda. Como controvérsia montada para se definir a humanidade dos índios, fez mobilizar o próprio sentido do que seja alma, humanidade e animalidade dos seres. 
parece dar-se conta das novidades, para ambos os lados, que emergem do encontro entre colonizadores e índios, mas essas conexões não são aí investigadas, inclusive porque exigiriam entradas demoradas e diligentes na vasta literatura etnológica ameríndia. 5 Quer dizer, se o tema é o encontro ("Luso-Brazilian encounters"), eu diria que o encontro revela-se muito mais como luso (encontro consigo mesmo) que brasileiro (encontro com o outro), na medida em que os brasileiros do século xvi muito mais se referem aos índios, isto é, os "brasis".

Sem dúvida que a perspectiva de Zir enriquece o nosso entendimento sobre o Velho Mundo. Mas como é muito atada a este e pouco aberta ao outro, permanecemos como que confinados à metade da história. É verdade que o autor atenta para essa falta, como quando assevera que "this book addresses what can only be called a style of thinking in the corpus of the Portuguese, which nonetheless incorporated, of course, elements coming from the Indians" (p. 6). Of course, logo concordaremos, mas ainda assim esses elementos indígenas não despontam, senão insuficientemente, nas descrições do autor. Para ele, "it is now impossible to consider any style of thinking that would have pertained to the Indians, independently from what was articulated by the Portuguese" (p. 6). Ou ainda: "it does not matter if the Iberian naturalists are in the Old or in the New World" (p. 10). Mas será mesmo que esse deslocamento do Velho para o Novo Mundo realmente não importa? Ora, é o próprio Ian Hacking, importante mentor de Zir, que atenta para os efeitos dos deslocamentos e das transposições, conforme citação do próprio Zir (nota 6, capítulo 1):

Isso é o que acontece quando nos movemos entre diferentes contextos. Movemonos, mas enquanto nos movemos também nos movemos a nós mesmos, isto é, usando uma metáfora, nós nunca conquistamos verdadeiramente o sonhador que sonha em nós.

This is what happens when one moves between different contexts. We move, but while moving we also move ourselves, that is, to use a metaphor: we never truly conquer the dreamer who dreams in us.

Ou seja, Zir poderia desdobrar consequências daí. Não sendo assim, teríamos então que supor - mas suposição pouco convincente, insisto - que o contato (tal entre portugueses e índios) não produziu mútua afetação, mútuo deslocamento. Já o acesso a imagens de pensamento ou mediações etnoestilísticas de enunciação dos ameríndios com os quais os portugueses se depararam, esse acesso não é rigorosamente impossí-

5 Para considerações preciosas sobre como ler as fontes historiográficas desse período, cf. Sztutman, 2012, em especial o tópico 2.3: "Notas para uma (re)leitura das fontes", constante no capítulo 2: "Os tupi antigos reencontrados". 
vel, ainda que demande um enorme e particular esforço, incluindo a leitura de fontes por vias indiretas, como, por exemplo, as legadas por religiosos e administradores coloniais portugueses. A esse respeito, aliás, vários historiadores e etnólogos americanistas já puderam indicar trilhas seguras. Apenas a título de exemplo, embora sejam exemplos paradigmáticos, menciono aqui os nomes de Florestan Fernandes, Hélène Clastres, Manuela Carneiro da Cunha, Eduardo Viveiros de Castro, John Monteiro e Renato Sztutman. Como quer que seja, com o livro de Zir aprendemos bastante sobre o Velho Mundo seiscentista, mas pouco sobre o encontro no Novo Mundo. $\mathrm{O}$ risco, como se pode depreender, é o do eurocentrismo.

Ao retomar as monumentais investigações de Sérgio Buarque de Holanda (1994 [1959]), Zir pôde confirmar a superposição, que não se paralisava em contradição, do realismo e do fantástico, tal como hoje denominamos, na mentalidade portuguesa dos viajantes e conquistadores do Novo Mundo - ou como ainda em Thomas de Aquino, mencionado por Zir (p. 44): "não há contradição entre a revelação e a razão" ("there is no contradiction between revelation and reason”). Mas é o próprio Sérgio Buarque, em passagem não mencionada por Zir, a lembrar que

todo o mundo lendário nascido nas conquistas castelhanas e que suscita eldorados, amazonas, serras de prata, lagoas mágicas, fontes de juventude, tendem antes a adelgar-se, descolorir-se ou ofuscar-se desde que se penetra na América lusitana (Holanda, 1994, p. 130).

Quer dizer, o exame minucioso das fontes sinaliza claramente a modulação que os portugueses experimentaram quando no Novo Mundo. Não há como escapar dessas modulações ou transformações na realidade do contato. Fosse esse o partido do autor, então estaríamos habilitados a compreender nos Seiscentos que no curso pragmático da ação social os colonizadores europeus e os ameríndios do Brasil dão-se as mãos, coisas e palavras vão juntas, não se opõem ou se contradizem, assim como o natural e o sobrenatural, o saber e a crença, a história e o mito, o sujeito e o objeto, o animado e o inanimado, o material e o simbólico, a descrição do real e sua simulação. Impossível que o contato não produza transformações. A esse respeito, lembremos, para terminar, os versos fulgurantes de Carlos Drummond de Andrade em "Relógio do rosário".

nada é de natureza assim tão casta que não macule ou perca a própria essência ao contato furioso da existência. 
OS EMBATES DO ENGONTRO

\section{Stelio MarRas}

Instituto de Estudos Brasileiros, Universidade de São Paulo, Brasil.

smarras@usp.br

\section{The shock of encounter}

\section{REFERÊNGIAS BIBLIOGRÁFIGAS}

Hacking, I. Historical ontology. Cambridge: Harvad University Press, 2002.

Holanda, S. B. de. Visão do paraíso: os motivos edênicos no descobrimento e colonização do Brasil. São Paulo:

Companhia das Letras, 1994 [1959].

Latour, B. Jamais fomos modernos: ensaio de antropologia simétrica. São Paulo: Editora 34, 1994. . A esperança de Pandora: ensaios sobre a realidade dos estudos científicos. Bauru: Edusc, 2001. Reflexão sobre o culto moderno dos deuses fe(i)tiches. São Paulo: Edusc, 2002.

PÉcora, A. Cartas à segunda escolástica. In: Novaes, A. (Org.). A outra margem do Ocidente. São Paulo: Companhia das Letras, 1999. p. 373-414.

Sahlins, M. Cosmologies of capitalism: The trans-Pacific sector of "The World System". Radcliffe-Brown Lecture in Social Anthropology. Proceedings of the British Academy 74, 1988, p. 1-51.

Shapin, S. \& Schaffer, S. Leviathan and the air-pump: Hobbes, Boyle, and the experimental life. Princeton:

Princeton University Press, 1985.

Stengers, I. Cosmopolitiques. Paris: La Découverte, 1997. . A invenção das ciências modernas. São Paulo: Editora 34, 2002.

Sztutman, R. O profeta e o principal: a ação política ameríndia e seus personagens. São Paulo: Edusp, 2012. 